\title{
Impact van een IC-behandeling: Post Intensive Care Syndroom
}

\author{
Annemiek Wolters en Martine Schuckman
}

intensive care

Post Intensive Care

Syndroom

COVID-19

bedrijfs- en verzeke

ringsgeneeskundige

begeleiding
Voorgaande jaren belandden in Nederland per jaar gemiddeld 80.000 mensen op de intensive care (IC), van wie er naar schatting 35.000 tussen de 18 en 67 jaar waren en die behoorden daarmee in ieder geval qua leeftijd tot de werkende populatie. ${ }^{1}$ Opnameredenen voor een IC-behandeling zijn divers, het betreft echter per definitie kritiek zieke en vitaal bedreigde patiënten. Een opname op een IC kan bijvoorbeeld nodig zijn na een operatie, na trauma, of als gevolg van een ernstige infectie. Menigeen zal op dit moment direct denken aan alle coronavirus disease 2019 (COVID-19) patiënten die recent een IC-behandeling nodig hadden of nog nodig hebben. Door de zogenoemde coronacrisis is er in de samenleving meer oog gekomen voor hoe ingrijpend een behandeling op de IC kan zijn voor het fysiek en mentaal functioneren. Een aanzienlijk deel van de patiënten houdt er jarenlang klachten aan over, vaak met een verminderde kwaliteit van leven en aanzienlijke beperkingen tot gevolg. ${ }^{2,3}$ De overkoepelende term die gebruikt wordt voor alle nieuw ontstane of verergerde klachten die patiënten ervaren als gevolg van de IC-behandeling is het Post Intensive Care Syndroom, oftewel PICS. ${ }^{3}$ Naar schatting ervaart 50-70\% van de patiënten die één jaar na de IC-behandeling nog in leven is klachten die vallen onder de noemer PICS. ${ }^{2,4}$

Middels dit artikel wordt inzicht geboden in de klachten behorende bij PICS. Daarna volgt een beschouwing van wat het effect van PICS kan zijn op het functioneren, de belastbaarheid en daarmee het arbeidsvermogen van patiënten. Vervolgens wordt er, gezien de actualiteit, stilgestaan bij de te verwachten langetermijnproblemen van COVID-19-patiënten met een IC-behandeling in het ziektebeloop en de specifieke zorg daaromtrent.

\section{Klachten passend bij het Post Intensive Care Syndroom \\ Fysieke klachten}

Patiënten hebben na een IC-behandeling fysiek gezien voornamelijk last van cardiopulmonale problemen en klachten van het bewegingsapparaat. Deze klachten zorgen ervoor dat patiënten nog geruime tijd een verminderde inspanningstolerantie kunnen hebben, een afgenomen spierkracht en een verminderde beweeglijkheid van gewrichten. Tevens kan er sprake zijn van IC verworven spierzwakte (ICU acquired weakness). Dit is pathofysiologisch een complexe functionele en structurele verandering van de zenuw en spier, leidend tot een polyneuropathie, polymyopathie of een combinatie van beiden. De IC verworven spierzwakte treft zowel de spieren van de ledematen als de ademhalingsspieren. Belangrijke risicofactoren voor het ontstaan van problemen in het fysiek functioneren zijn het doormaken van een sepsis, meervoudig orgaanfalen, langdurige beademing en immobilisatie..$^{2,5}$ Naar schatting ervaart ongeveer de helft van de patiënten die langer dan twee dagen op de IC heeft gelegen één jaar na ontslag nog belemmeringen in het fysiek functioneren. ${ }^{6}$

\section{Cognitieve klachten}

Er bestaat een risico op het ontwikkelen van cognitieve stoornissen na een IC-behandeling. Cognitieve problemen kunnen zich in alle domeinen voordoen, waarbij geheugen en executieve functies het meest frequent zijn aangedaan. De ernst van de klachten varieert van subtiele veranderingen tot complete afhankelijkheid in zelfzorgactiviteiten. Belangrijke risicofactoren voor het ontstaan van cognitieve problemen zijn onder andere het doormaken van een delirium en de ernst van de ziekte. De prevalentie blijkt lastig in te schatten en hangt onder andere af van de gebruikte neuropsychologische testen, de definitie van een cognitieve stoornis en de follow-up duur. Een range van 4-62\% wordt in de literatuur genoemd, bij een follow-up duur variërend van 2-156 maanden., ${ }^{2,7}$

\section{Psychische klachten}

Psychische klachten komen frequent voor na een IC-behandeling. Ook hier varieert de ernst van de klachten. Klachten kunnen passen bij een fulminante klinische psychiatrische stoornis zoals een angststoornis, depressie of een posttraumatische stressstoornis (PTSS), of er kunnen mildere psychische problemen spelen zoals bijvoor- 


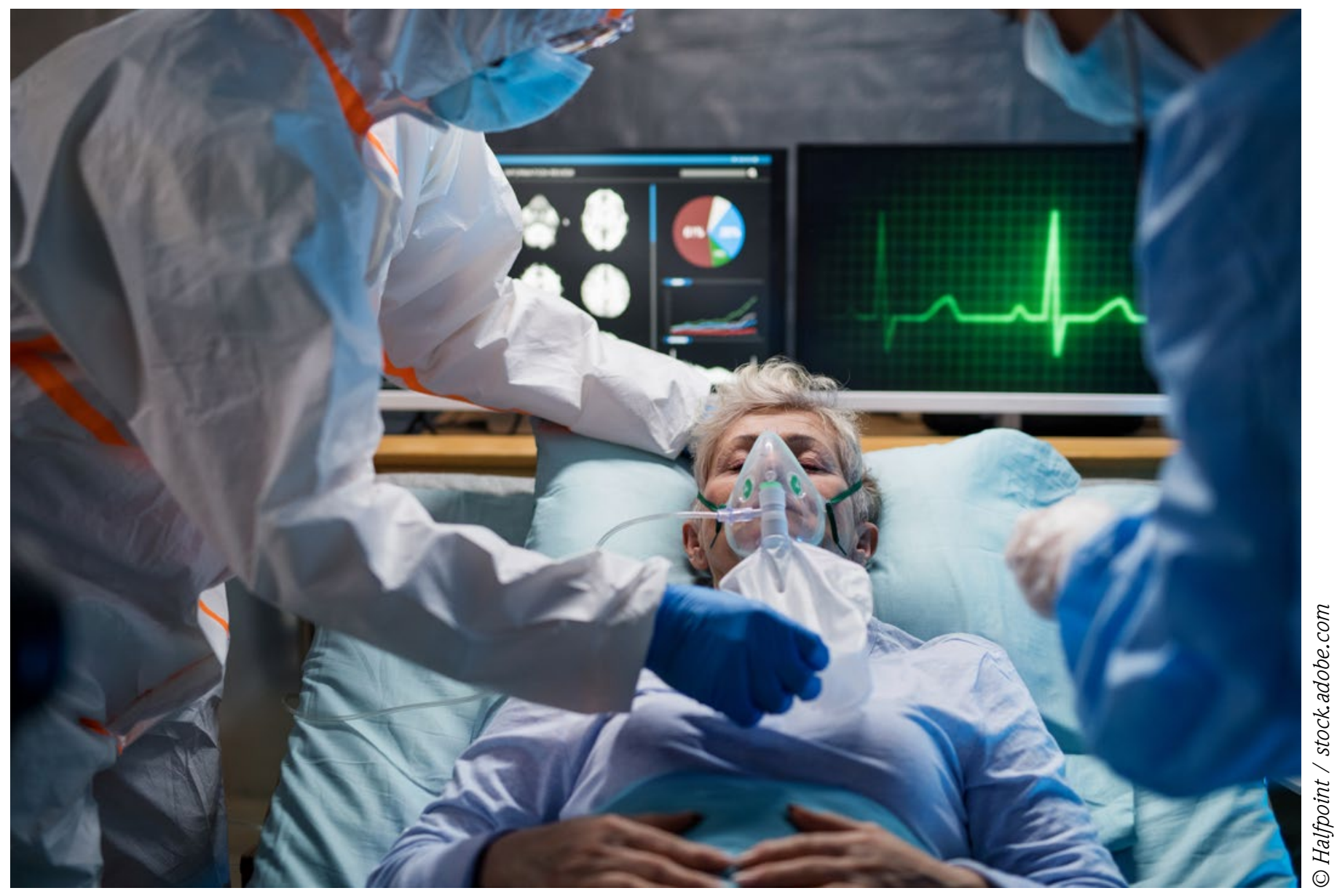

beeld zingevingsproblematiek. ${ }^{2}$ Risicofactoren voor het ontwikkelen van psychische klachten zijn pre-existente psychiatrische aandoeningen, het gebruik van benzodiazepines tijdens de IC-behandeling en herinneringen aan angstige momenten op de IC. ${ }^{2}$ Ongeveer $30 \%$ van de patiënten ervaart het eerste jaar na ontslag angstklachten, depressieve klachten of klachten die passen bij PTSS. ${ }^{2}$ Ook naasten kunnen last hebben van angstige of depressieve gevoelens, waardoor zij belemmeringen in het functioneren ervaren. De klachten die naasten van een IC-patiënt ervaren worden ook wel aangeduid als de PICS van de familie, oftewel PICS-F. ${ }^{3}$

\section{Het effect van PICS op het arbeidsvermogen} Er is weinig onderzoek gedaan naar werkhervatting na een IC-behandeling. Uit een eerdere grote cohortstudie, waarbij alle IC-patiënten tussen de 18 en 65 jaar die vóór de IC-opname werkten werden geïncludeerd, mits zij minimaal 72 uur op de IC verbleven en levend het ziekenhuis verlieten, bleek dat na één jaar $60 \%$ weer werkte. Na drie jaar was dat percentage opgelopen tot $75 \%$. Hoeveel procent van deze populatie PICS-klachten had wordt echter niet vermeld. Tevens wordt niet besproken of de ex-IC patiënten nog functioneerden op het niveau van vóór de IC-opname, of dat er aanpassingen aan de werkomgeving nodig waren.
Om goede begeleiding rondom werkhervatting te kunnen bieden aan patiënten met PICS is het essentieel dat de klachten en de belastbaarheid van de patiënten adequaat en zorgvuldig in beeld worden gebracht. Om de vertaalslag van ervaren belemmeringen naar belastbaarheid te maken is het van belang dat we de complexiteit van de problematiek herkennen en erkennen. Het betreft vaak een combinatie van fysieke, cognitieve en psychische klachten. Welke belemmeringen patiënten ervaren als gevolg van de klachten is door de variatie in ernst en diversiteit van klachten niet eenduidig te vatten en hangt ook samen met andere factoren, zoals bijvoorbeeld coping. Uit praktijkervaring blijkt dat patiënten in het begin van de herstelperiode vaak veel last van de fysieke klachten hebben en dat zij aan het revalideren zijn naar een niveau waarop zij weer zelfstandig zelfzorgactiviteiten uit kunnen voeren. In die periode zijn zij niet inzetbaar voor arbeid. Wanneer zij vervolgens herstellen tot een niveau van zelfredzaam functioneren, dan is de volgende stap om het maatschappelijk functioneren weer op te pakken. Op dat moment komen patiënten er vaak achter dat zij vastlopen op cognitieve en psychische problemen. Ze merken bijvoorbeeld dat het werk te snel voor ze gaat, dat ze moeite hebben met het aanleren van nieuwe activiteiten of dat ze veel vergeten. Ook vermoeidheid speelt geregeld een belangrijke rol. In termen van de 
Functionele Mogelijkheden Lijst kunnen op alle rubrieken beperkingen gelden. Welke beperkingen dat precies zullen zijn is individueel bepaald. De behandeling en begeleiding van PICS-patiënten vraagt om maatwerk (matched care). Een zorgvuldige anamnese met aandacht voor zowel het fysiek, als cognitief en psychisch functioneren is essentieel. Zo nodig kan gedegen aanvullend onderzoek meer duidelijkheid bieden.

\section{PICS na COVID-19}

Er is nog onvoldoende gedegen bewijslast over wat de langetermijngevolgen van een doorgemaakte COVID-19 gaan zijn. Er is een relatief grote Nederlands/Belgische studie gedaan naar zelfgerapporteerde klachten drie maanden na het doormaken van een COVID-19, zowel met als zonder ziekenhuisopname in het beloop. Patiënten die een IC-behandeling nodig hadden werden in deze studie geëxcludeerd. Een enorme diversiteit aan klachten werd gerapporteerd. Vermoeidheid en dyspnoe bleken in deze studie de twee meest voorkomende klachten te zijn. De auteurs stellen dat de bevindingen suggestief zijn voor het bestaan van een post-COVID-19syndroom. Aanvullend onderzoek is nodig om dit verder uit te zoeken. ${ }^{9}$

Als we specifiek kijken naar de groep patiënten met een doorgemaakte COVID-19 en een IC-behandeling in het ziektebeloop dan is het aannemelijk dat minstens een deel van deze groep symptomen van PICS zal hebben. Met betrekking tot de fysieke klachten kan deze groep patiënten mogelijk bovengemiddeld vaak pulmonale problemen hebben. Van een COVID-19-pneumonie is nog onvoldoende bekend in hoeverre deze restschade geeft. Uit eerdere studie van doorgemaakte pneumonieën veroorzaakt door een gerelateerd coronavirus blijkt echter dat er bij deze patiënten sprake kan zijn van aanzienlijke pulmonale restschade. ${ }^{10}$ Tevens hebben enkele COVID-19-patiënten mechanische beademingen met hoge druk nodig gehad. Het is bekend van mechanische beademing met hoge druk dat dit pulmonale schade kan geven. ${ }^{11}$ Pulmonale schade geeft symptomatisch vaak een verminderd inspanningsvermogen en dyspnoe. Daarnaast heeft een deel van de COVID-19-patiënten trombo-embolische complicaties doorgemaakt, zoals longembolieën, een myocardinfarct of cerebrale infarcering. ${ }^{12}$ Een complicatie van doorgemaakte longembolieën is pulmonale hypertensie, wat zich evenals pulmonale restschade als een verminderde inspanningstolerantie en dyspnoe kan presenteren. Daarnaast kan een eventueel doorgemaakt myocardinfarct met myocardschade ook een verminderde inspanningstolerantie en dyspnoe geven. Het advies vanuit de Federatie Medisch Specialisten is om patiënten met aanhoudende klachten laagdrempelig door te verwijzen naar de longarts. Andere aandachtspunten voor de nazorg van COVID-19-patienten met fysieke problemen zijn gedoseerd conditie opbouwen, zo nodig met hulp van een fysiotherapeut of ergotherapeut.

Ook is het van belang dat er aandacht is voor een adequate voedingstoestand. Voldoende eiwitinname is hierbij essentieel. Een verwijzing naar een diëtist is in deze te overwegen. ${ }^{13}$ Cognitieve klachten kunnen zich voordoen als direct gevolg van cerebrale infarcering. Daarnaast is bekend dat een deel van de COVID-19-patienten een delier heeft doorgemaakt, wat een risicofactor is voor het ontwikkelen van cognitieve klachten. ${ }^{7,14}$ Bij aanhoudende cognitieve klachten kan overwogen worden om de patiënt neuropsychologisch te laten onderzoeken, bijvoorbeeld bij een geheugenpoli of via een medisch expertisecentrum. ${ }^{13}$ Het is de verwachting dat overlevenden van COVID-19 bovenmatig veel psychische klachten zullen hebben als gevolg van de bijzondere omstandigheden waarin zij ziek zijn geweest. Deze patiënten hebben een levensbedreigende ziekte gehad in de context van een pandemie. Ze hebben doorgaans langdurig geen bezoek mogen ontvangen. De beschermende kleding van de zorgverleners werd vaak als beangstigend ervaren en stond het normale empathische contact tussen zorgverlener en patiënt in de weg. Daarnaast is er veel onzekerheid ten aanzien van perspectief en beloop (geweest), wat beangstigend kan zijn voor patiënten. ${ }^{13}$ Een verwijzing naar een eerstelijnspsycholoog, maatschappelijk werk of de specialistische GGZ valt bij patiënten met psychische klachten te overwegen. ${ }^{13}$ Er zijn multidisciplinaire teams gestart die de nazorg voor COVID-19-patiënten trachten te centraliseren en optimaliseren. Het Coronazorgteam is hier een voorbeeld van (www.coronazorgteam.nl, geraadpleegd 12-10-2020).

Om de belastbaarheid van patiënten met een doorgemaakte COVID-19 te bepalen gelden de adviezen zoals deze ook voor andere patiënten met PICS gelden; klachten en ervaren belemmeringen zorgvuldig in kaart brengen op basis van een uitgebreide anamnese, kennis nemen van de bevindingen uit de curatieve sector en aanvullend onderzoek indien daar een indicatie voor is.

\section{Conclusie}

Het Post Intensive Care Syndroom is een verzamelnaam voor alle nieuw ontstane of verergerde fysieke, cognitie ve en psychische klachten na een IC-behandeling. Er is een enorme variatie in ernst en diversiteit van klachten. Zorg voor patiënten met PICS vraagt om kennis van PICS, in combinatie met een zorgvuldige uitgebreide anamnese en zo nodig aanvullend onderzoek. Dit is zowel van belang voor het leveren van adequate zorg, als om een gedegen vertaalslag te maken van ervaren belemmeringen naar belastbaarheid in deze groep patiënten. Gezien het hoge aantal IC-behandelingen van de afgelopen maanden als gevolg van COVID-19 is de verwachting dat bedrijfs- en verzekeringsgeneeskundigen 


\section{Aandachtspunten}

- Het Post Intensive Care Syndroom is een overkoepelende term die alle nieuw ontstane of verergerde fysieke, cognitieve en psychische klachten na een IC-behandeling omschrijft.

- Er is een enorme variatie in ernst en diversiteit van klachten passend bij het Post Intensive Care Syndroom.

- Zorg voor patiënten met het Post Intensive Care Syndroom vraagt om kennis van het syndroom, in combinatie met een zorgvuldige uitgebreide anamnese en zo nodig aanvullend onderzoek.

- Gezien het hoge aantal IC-behandelingen van de afgelopen maanden als gevolg van COVID-19 is de verwachting dat bedrijfs- en verzekeringsgeneeskundigen de komende tijd in toenemende mate geconfronteerd zullen worden met patiënten met het Post Intensive Care Syndroom.
2. Kerckhoffs MC, Soliman IW, Wolters AE et al. Langetermijnuitkomsten van IC-behandeling. Ned Tijdschr Geneeskd. 2016;160:A9653.

3. Needham DM, Davidson J, Cohen H, et al. Improving longterm outcomes after discharge from intensive care unit: report from a stakeholders' conference. Crit Care Med. 2012;40:502509.

4. Geense W, Zegers M, Vermeulen H, et al. Changes in frailty among ICU survivors and associated factors: Results of a oneyear prospective cohort study uwing the Dutch Clinical Frailty Scale. J Crit Care. 2020;55:184-193.

5. Kress JP, Hall JB. ICU-Acquired weakness and recovery from critical illness. N Engl J Med. 2014;370:1626-1635.

6. Van der Schaaf M, Beelen A, Dongelmans DA, et al. Functional status after intensive care: a challenge for rehabilitation professionals to improve outcome. J Rehabil Med. 2009;41:360-366.

de komende tijd in toenemende mate geconfronteerd zullen gaan worden met patiënten met PICS. De eerste bewijslast laat zien dat vermoeidheid en dyspnoe mogelijk belangrijke symptomen op de lange termijn zullen zijn. Laten we ervoor zorgen dat we met gedegen kennis van deze aandoening deze groep werknemers, die een ernstige ziekte met enorme impact heeft doorgemaakt, adequaat begeleiden in hun traject naar werkhervatting.

\section{Belangenconflicten}

Beide auteurs zijn werkzaam bij Ergatis, Medisch Expertise Centrum voor Arbeid en Gezondheid. Het artikel is tijdens werktijd tot stand gekomen. Ergatis vervult als expertisecentrum een centrale rol in het vaststellen van de belastbaarheid van patiënten, voornamelijk indien er sprake is van complexe problematiek. De kennis in dit artikel is ook gebruikt om binnen Ergatis gepaste zorg te kunnen leveren aan patiënten met het Post Intensive Care Syndroom en patiënten met een doorgemaakte COVID-19.]

\section{Literatuur}

1. Nationale Intensive Care Evaluatie. Jaarboek 2018 Het nut van de NICE-registratie. Stichting NICE. 2019.
7. Wolters AE, Slooter AJC, van der Kooi AW, van Dijk D. Cognitive impairment after intensive care unit admission: a systematic review. Intensive Care Med. 2013;39:376-386.

8. Riddersholm S, Christensen S, Kragholm K, et al. Organ support therapy in the intensive care unit and return to work: a nationwide, register-based cohort study. Intensive Care Med, 2018;44:418-427.

9. Goërtz YMJ, Van Herck M, Delbressine JM, et al. Persistent symptoms 3 months after a SARS-CoV-2 infection: the post-COVID-10 syndrome? ERJ Open Res. 2020; in press.

10. Salehi S, Reddy S, Gholamrezanezhad A. Long-term pulmonary consequences of Coronavirus Disease 2019 (COVID-19) What we know and what to expect. J Thorac imaging. 2020;35(4):W87-W89.

11. Slutsky AS, Marco Ranieri V. Ventilator-Induced lung injury. N Eng J Med. 2013;369:22.

12. Klok FA, Kruip MJHA, van der Meer NJM et al. Incidence of thrombotic complications in critically ill ICU patients with COVID-19. Thromb Res. 2020; 191:145-147.

13. Kennisinstituut van de Federatie Medisch Specialisten. Leidraad Nazorg voor IC-patiënten met COVID-19. Versie 10 april 2020.

14. Kennisinstituut van de Federatie Medisch Specialisten. Leidraad: Nazorg voor patiënten met COVID-19. Versie 28 mei 2020. 